\title{
Use of a prefabricated pectoralis major muscle flap and pedicled jejunal interposition graft for salvage esophageal reconstruction after failed gastric pull-up and colon interposition
}

\author{
K. Robert Shen, MD, ${ }^{a}$ William Gerald Austen, Jr, MD, ${ }^{\mathrm{b}}$ and Douglas J. Mathisen, MD, ${ }^{a}$ Boston Massachusetts
}

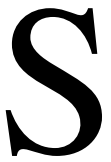

econdary reconstruction after failed esophageal surgery remains a challenging surgical problem. In circumstances when neither the stomach nor the small or large bowel is available or adequate as an esophageal replacement, skin or musculocutaneous flaps should be considered. We report a case of salvage esophageal reconstruction using a prefabricated muscle flap in combination with pedicled jejunum in a staged fashion that highlights some of the management issues in addressing this difficult clinical situation.

\section{Clinical Summary}

A 50-year-old man with a history of Barrett's esophagus was found to have invasive adenocarcinoma in the distal third of his esophagus during surveillance endoscopy. He underwent en bloc esophagogastrectomy with 3-field lymph node dissection. On the fourth postoperative day ischemic necrosis of the gastric conduit developed, and the distal third of the conduit was resected. The left colic artery was sclerotic, so an isoperistaltic right colon interposition graft was used to connect the cervical esophagus to the gastric conduit remnant. Two weeks later, a right-sided empyema developed, and the colon interposition graft was found to be infarcted. The patient underwent decortication of the right lung and excision of the necrotic colon graft, and a cervical esophagostomy was created. Five months after the initial operation, the patient was referred to Massachusetts General Hospital/Harvard Medical School for an opinion on the options for esophageal reconstruction.

Esophageal reconstruction was performed using a delayed, prelaminated, and tubularized pectoralis major muscle flap and pedicled jejunal interposition graft in a series of 3 staged procedures. The first procedure was prelamination and delay of a right-sided pectoralis major muscle flap. A large fasciocutaneous flap was elevated to expose the entire pectoralis muscle. After the superior and lateral vascular bundles entering the pectoralis major were divided, a splitthickness skin graft from the right thigh was sutured over the entire muscle flap. The fasciocutaneous flap was then returned to the chest

From the Divisions of General Thoracic Surgery, ${ }^{\mathrm{a}}$ and Plastic and Reconstructive Surgery, ${ }^{\mathrm{b}}$ Massachusetts General Hospital/Harvard Medical School, Boston, Mass

Received for publication March 23, 2007; accepted for publication Aug 14, 2007.

Address for reprints: K. Robert Shen, MD, Division of General Thoracic Surgery, Mayo Clinic, 200 First St SW, Mayo Building 1263W, Rochester, MN 55905 (E-mail: shen.krobert@mayo.edu).

J Thorac Cardiovasc Surg 2008;135:1186-7

$0022-5223 / \$ 34.00$

Copyright $(\odot 2008$ by The American Association for Thoracic Surgery doi:10.1016/j.jtcvs.2007.08.079

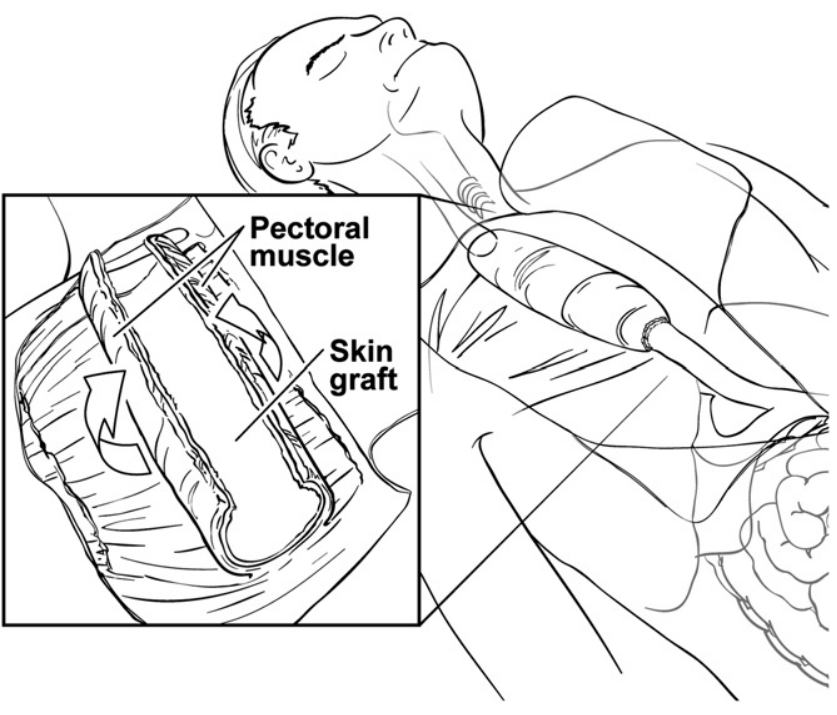

Figure 1. Schematic drawing illustrating the completed reconstruction and steps used to create the prefabricated pectoralis major flap. A portion of the costal arch has been resected to allow the jejunum to reenter the abdomen without being stretched over the ribs.

wall to cover the entire construct. One month later the pectoralis major flap was elevated, and the thoracoacromial vessels were divided, leaving the flap based on the internal thoracic artery perforators medially. The flap was tubularized by rolling it to create a skin-lined tube $22 \mathrm{~cm}$ in length. The proximal end of the tube was anastomosed to the distal cervical esophagus. The fasciocutaneous chest wall flap was advanced to cover the neoesophagus. At the distal end of the neoesophagus, the tube was sutured to the abdominal wall skin. This allowed salivary secretions to drain into an ostomy appliance affixed to the abdominal wall. Two months later a laparotomy was performed, and a Roux-en-Y jejunal segment was anastomosed to the distal end of the tubularized pectoralis major muscle flap (Figure 1). On postoperative day 7, the patient underwent a barium swallow that showed no anastomotic leaks with contrast flowing rapidly to the jejunum. The patient was able to discontinue enteral tube feedings and now is able to obtain $100 \%$ of his nutrition orally. Figure 2 shows the patient at the time of discharge from the hospital after the completed reconstruction.

\section{Discussion}

Anastomotic leak rates as high as $22 \%$ and stricture rates of $8 \%$ reported in published series, as well as poor functional results, have 


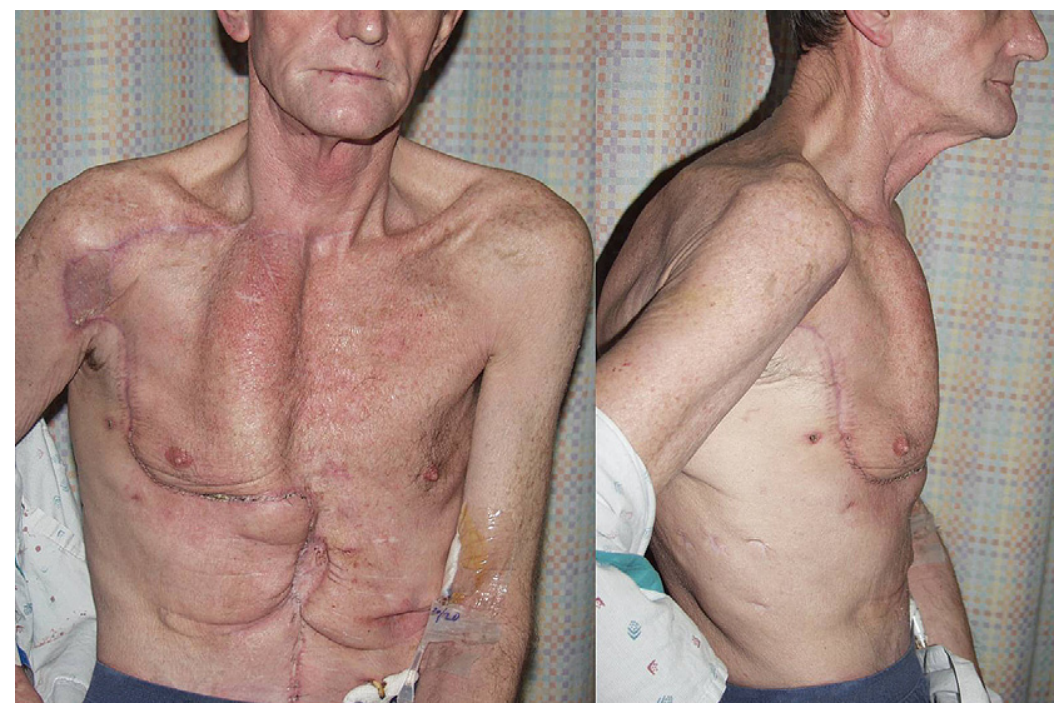

Figure 2. The patient before discharge from the hospital after the final stage of the reconstruction.

limited the use of skin and muscle flaps for esophageal reconstruction. ${ }^{1}$ These flaps also have a number of disadvantages compared with alimentary tract esophageal substitutes. They may not be long enough if the esophageal defect is long and have poor motility resulting in inferior functional outcome. As a result, skin and muscle flaps are considered the last choice and generally only used when alternative abdominal viscera are unavailable or of insufficient length., ${ }^{2,3}$ A recent report on the successful use of supercharged pedicled jejunal flaps for total esophageal reconstruction may provide an additional alternative. ${ }^{4}$ Prefabrication of skin flaps used for esophageal reconstruction has been shown to provide superior results to conventional single-stage techniques. ${ }^{5}$ In this patient, with a long segment of esophageal defect and limited replacement conduit options, a staged approach allowed the higher risks inherent in using a muscle flap to be mitigated. By optimizing conditions for the flap to heal, and allowing it to heal before proceeding on to the next phase of reconstruction, the patient was not exposed to the risk of failure of the flap until the final stage of the procedure.

By combining pedicled jejunum with a musculocutaneous flap, 2 of the other disadvantages of using skin/muscle flaps for esophageal reconstruction (inability to bridge long esophageal defects and the poor motility of skin tubes) could also be addressed. In the rare situations in which skin/muscle flaps need to be used for esophageal reconstruction, prefabrication techniques and a staged approach provide significant advantages over single-stage methods and should be considered in patients with difficult cases.

\section{References}

1. Chen H-C, Tang Y-B. Microsurgical reconstruction of the esophagus. Semin Surg Oncol. 2000;19:235-45.

2. Moreno-Osset E, Tomas-Ridocci M, Paris F, Mora F, Garcia-Zarza A, Molina R, et al. Motor activity of esophageal substitute (stomach, jejunal and colon segments). Ann Thorac Surg. 1986;41:515-9.

3. Okazaki M, Asato H, Takushima A, Nakatsuka T, Ueda K, Harii K. Secondary reconstruction of failed esophageal reconstruction. Ann Plast Surg. 2005;54:430-537.

4. Ascioti AJ, Hofstetter WL, Miller MJ, Rice DC, Swisher SG, Vaporciyan AA, et al. Long-segment, supercharged, pedicled jejunal flap for total esophageal reconstruction. $J$ Thorac Cardiovasc Surg. 2005; 130:1391-8.

5. Chen J-C, Kuo Y-R, Hwand T-L, Chen H-H, Chang C-H, Tang Y-B. Microvascular prefabricated free skin flaps for esophageal reconstruction in difficult patients. Ann Thorac Surg. 1999;67:911-6. 